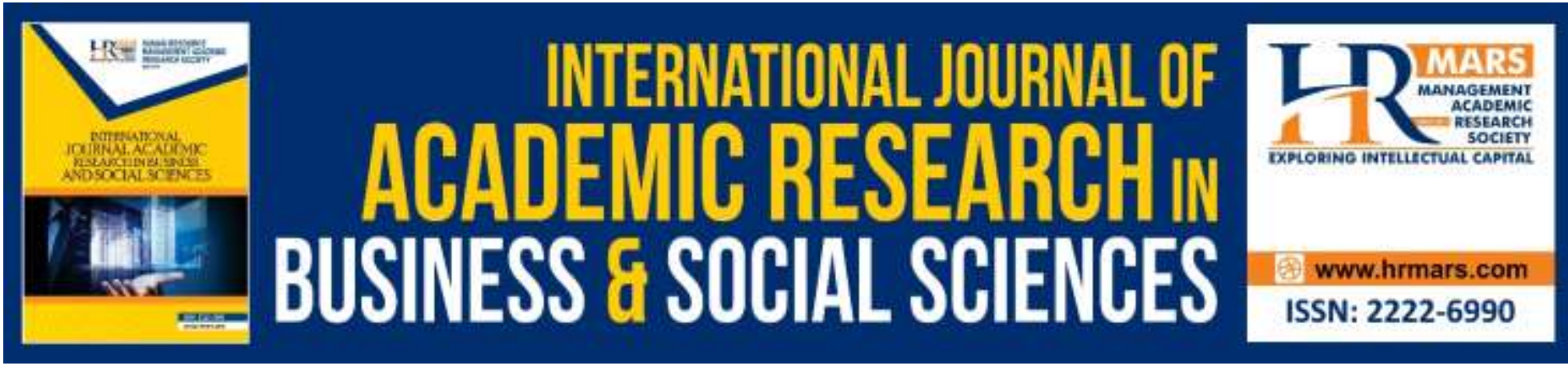

\title{
Help-Seeking Behaviour of University Students During Covid- 19 Pandemic: Psychological Openness, Indifference to Stigma, Help-Seeking Propensity
}

Xing Lee \& Khee Hoong Ho

To Link this Article: http://dx.doi.org/10.6007/IJARBSS/v11-i17/11392

DOI:10.6007/IJARBSS/v11-i17/11392

Received: 05 August 2021, Revised: 06 September 2021, Accepted: 27 September 2021

Published Online: 07 October 2021

In-Text Citation: (Lee \& Ho, 2021)

To Cite this Article: Lee, X., \& Ho, K. H. (2021). Help-Seeking Behaviour of University Students During Covid-19 Pandemic: Psychological Openness, Indifference to Stigma, Help-Seeking Propensity. International Journal of Academic Research in Business and Social Sciences, 11(17), 70-79.

Copyright: (C) 2021 The Author(s)

Published by Human Resource Management Academic Research Society (www.hrmars.com)

This article is published under the Creative Commons Attribution (CC BY 4.0) license. Anyone may reproduce, distribute, translate and create derivative works of this article (for both commercial and non-commercial purposes), subject to full attribution to the original publication and authors. The full terms of this license may be seen at: http://creativecommons.org/licences/by/4.0/legalcode

Special Issue Title: Empowering Community and Beyond, iRandau, 2021, Pg. $70-79$

Full Terms \& Conditions of access and use can be found at http://hrmars.com/index.php/pages/detail/publication-ethics 


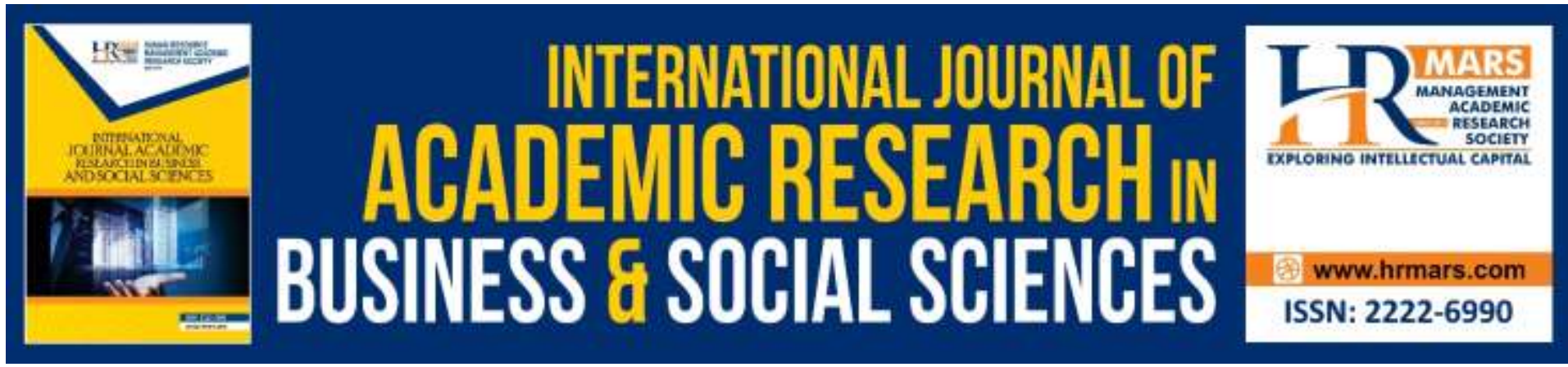

\title{
Help-Seeking Behaviour of University Students During Covid-19 Pandemic: Psychological Openness, Indifference to Stigma, Help-Seeking Propensity
}

\author{
Xing Lee \& Khee Hoong Ho \\ Universiti Tunku Abdul Rahman \\ Email: hokh@utar.edu.my
}

\begin{abstract}
Since the pandemic outbreak, the Malaysian government has implemented Movement Control Order (MCO) in March 2020 to constrict the civilian's movements in an effort to contain the spread of the Corona Virus. Under the effect of MCO, individuals who were not working within the essential services were encouraged to remain stationary in their place of residence. Currently, multiple states in Malaysia are still under the Conditional Movement Control Order (CMCO) effect. Therefore, most post-secondary students have not regained the complete freedom to move freely and were isolated in their respective campuses. This group of individuals have been separated from their friends and family for several months in a stretch, reducing their much-needed psychological support. During these trying times, online help-seeking becomes an essential outlet for people to cope with their daily struggles and issues. Although the Covid-19 counselling hotline was introduced to outreach the general populace, help-seeking rates remained low. This study addresses the gap mentioned above by assessing the relationships between help-seeking intention, psychological openness, indifferent to stigma, and help-seeking propensity. A correlational survey study was conducted across Malaysia. The participants are university students aged between 18 to 29 who were recruited using the purposive sampling method. A total of 303 respondents participated in this survey. $62.7 \%$ were females $(n=190)$, while the remaining $37.3 \%$ were males $(n=113)$. Surprisingly, findings revealed that help-seeking intention was negatively correlated with psychological openness and indifferent to stigma (perceived public stigma and self-stigma). However, the help-seeking intention was found to correlate positively with help-seeking propensity. Counsellors, mental health practitioners, helpline operators, and educators may utilize the exploratory data from this study to devise preventative measures in increasing the individuals' intention to seek help from professionals for their mental and psychological health. In addition, university students could be benefited by dispelling the stigma of receiving counselling and increasing their awareness in seeking help.
\end{abstract}

Keywords: Help-seeking Intention, Psychological Openness, Indifferent to Stigma, HelpSeeking Propensity, University Students 


\section{Help-Seeking Behaviour During the COVID-19 Pandemic}

As of November 2020, the Covid-19 pandemic has infected over 56 million people worldwide (Coronavirus Cases, 2020). The Malaysian government has announced implementing the Conditional Movement Control Order (CMCO) on most of all states in Malaysia to control the spread of the Covid-19 (Khalid, 2020). Movements were restricted, and all citizens were urged to stay at home (Shanmugam et al., 2020). In this tumultuous time, online help-seeking becomes an important way for people to cope with their issues (Luo et al., 2020). Covid-19 counselling hotline has been activated to provide professional counselling services for people who need helps (Hasmuk et al., 2020), but the help-seeking rates remained low (Liang et al., 2020). During Covid-19, only $29.4 \%$ of participants with psychological distress seek professional help, such as a psychological assistance helpline and psychological counselling agency (Zhang et al., 2020). According to Ibrahim et al (2019), young people seeking help for a mental health issue are low compared with their mental illness rates. Based on Liang et al. (2020), the rate of students seeking help for psychological problems was still low during the Covid-19 pandemic. Even many higher education students face high levels of psychological distress, and they choose not to seek help or support for their difficulties (Laidlaw et al., 2016). Psychological openness is a significant positive predictor of intention to seek help (Alexi et al., 2018). The concept of psychological openness deduces an internal state of individuals instead of their external expression or behaviour (Tschofen \& Mackness, 2012). The public has become emotionally unstable due to the increasing infections during the Covid-19 pandemic (Zhang et al., 2020). According to Fonseca et al (2018), a lower level of psychological openness was found among individuals with insecure attachment, which means that they are less willing to disclose their problems and issues to health professionals.

Numerous studies have reported the stigma factors correlated with an individual's intention to seek help (Umubyeyi et al., 2016; Ibrahim et al., 2019; Liang et al., 2020). Based on Corrigan (2004), stigma is a significant barrier for people to seek help from mental health professionals. Individual's stigma towards mental illness may lead them to less intention to seek help for their psychological issues (Pham et al., 2020). A similar result also found in the study conducted by Kamimura et al (2018). They reported that stigma against mental illness would bring negative results towards help-seeking behaviours from mental health professionals.

Mackenzie et al. (2014) highlighted that individuals' help-seeking propensity is a strong predictor of their intentions to seek help. According to Ajzen \& Kuhl (1985), this intention level may lead to their actual help-seeking behaviour. Research conducted by Pham et al. (2020) reported that help-seeking propensity is the main variable that significantly influences students' intention in seeking help for their psychological health. Similar results have also reported in various studies that help-seeking propensity has been identified as a reliable predictor of individuals' help-seeking behaviour (Troeung et al., 2015).

Most of the research focuses on the effectiveness of treatments in hospitals during this pandemic (Lang, 2020). Interestingly, a study conducted by Lang et al. (2020) found out that most of the participants have a higher desire to understand community health care, case detection, and public communications during Covid-19. Similar results reported in the survey conducted by The Global Health Network (2020) indicated that studies related to individual's help-seeking behaviour are more needed than clinical trials.

Many students cannot complete their degrees while facing mental health issues through their studies (Kirsh et al., 2016). According to Auerbach et al (2016), university students are experiencing increasing rates and severity of mental health problems. Yee (2018) also indicated that undergraduate students are more likely to be at risk of suffering mental illness 
within the age group. Many studies have investigated and explored the mental health problem and help-seeking behaviour of caregivers, patients, workers, children and the general population during the Covid-19 pandemic, but there is very little attention that focuses on the population of undergraduate students (Son et al., 2020). Based on Liang et al (2020), the population of college students should not be ignored during this special period. Besides that, Liang et al (2020) found out that counselling and mental health services are underutilized among college students as they tend to bear the difficulties by themselves rather than seeking help. Brown et al (2020) reported that it is important to encourage helpseeking behaviour during Covid-19. Reducing the barriers to help-seeking behaviours and effective treatment of mental disorders may recover and improve the undergraduates' educational and psychosocial functioning, resulting in substantial long-term benefits (Pham et al., 2020). Knowing the factors that affect individuals help-seeking behaviour in this study may help mental health professionals reduce the barriers and improve university students' intention to seek help.

\section{Research Hypotheses}

The model that we are proposing is depicted in Figure 1. This research aims to study the relationships of help-seeking behaviour, psychological openness, indifference to stigma, and help-seeking propensity. In this research, help-seeking behaviour represents the dependent variable, whereas psychological openness, indifference to stigma, and help-seeking propensity represent the independent variables.

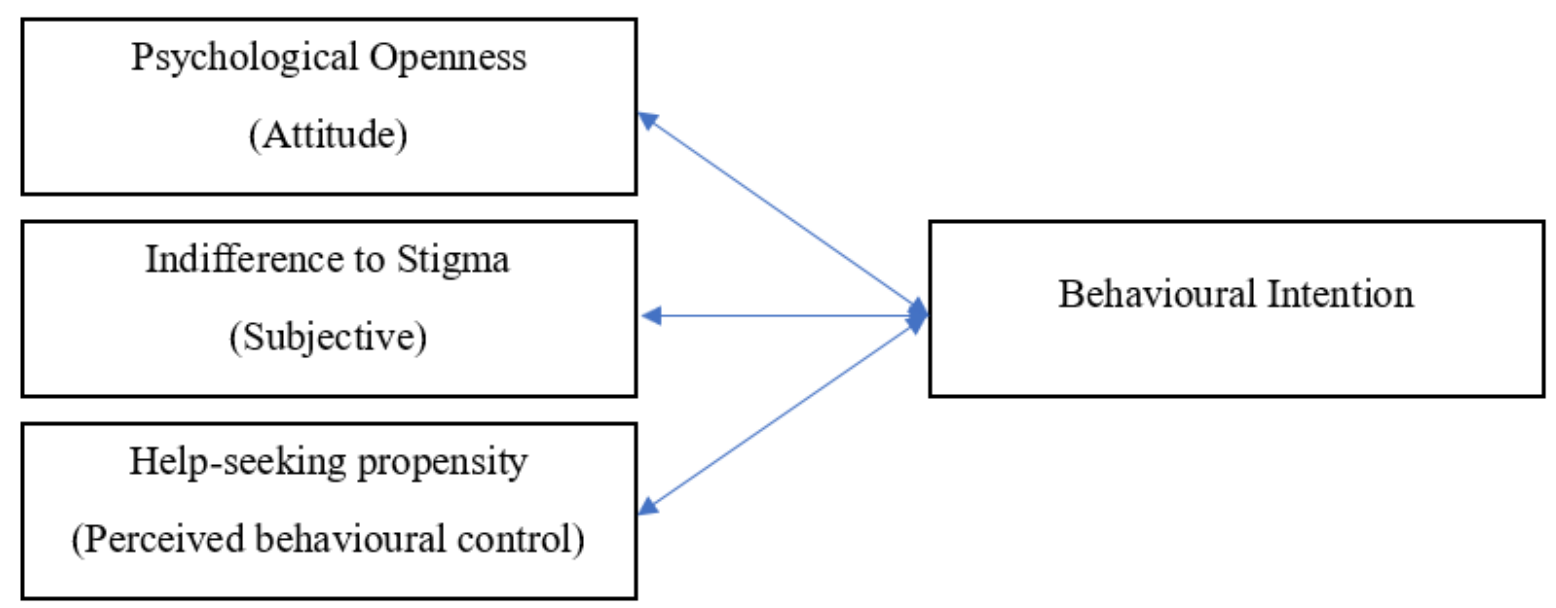

Figure 1: The conceptual framework of help-seeking behaviour, psychological openness, indifference to stigma, and help-seeking propensity.

$\mathrm{H}_{1}$ : There is a positive relationship between help-seeking intention and psychological openness.

$\mathrm{H}_{2}$ : There is a negative relationship between help-seeking intention and perceived public stigma.

$\mathrm{H}_{3}$ : There is a negative relationship between help-seeking intention and self-stigma.

$\mathrm{H}_{4}$ : There is a positive relationship between help-seeking intention and help-seeking propensity. 


\section{Method}

\section{Participants}

Purposive sampling was used to recruit Malaysian undergraduate students who are currently enrolled in university courses. Google Form was used to create an anonymous survey questionnaire posted through different social media platforms, such as Facebook, Messenger, WhatsApp, and Microsoft Teams. This study was conducted and distributed across Malaysia, with a total of 13 states. A total of 303 respondents aged between 18 to 29 took part in the current study. $62.7 \%$ were female respondents $(n=190)$ and $37.3 \%$ were male respondents $(n=113) .69 .7 \%$ of the respondents were undergoing their bachelor's degree $(n=211)$, followed by foundation ( $n=78 ; 25.7 \%)$, diploma $(n=11 ; 3.6 \%)$, and postgraduate degree ( $n$ $=3 ; 1 \%)$.

\section{Procedures}

An online questionnaire was generated using Google Form and was shared on social media via Messenger, Facebook, WhatsApp, and Microsoft Teams. The online survey questionnaire consisted of a consent form, followed by demographic information, the Mental Help-Seeking Attitudes Scale (MHSAS), two subscales of Inventory of Attitudes toward Seeking Mental Health Services (IASMHS), and the Perceived Stigma and Barriers to Care for Psychological Problems. Participation in this study is completely voluntary. Participants are free to withdraw and discontinue anytime without prejudice. Participants may only proceed to the questionnaire only after they have given their consent. The inclusion criteria of sample selection involved: (1) aged between 18- to 29-year-old; and (2) currently enrolling in higher education. Students below 18-year-old have been excluded due to the difficulty of obtaining immediate parental consent for participating in this research. In addition, students above 29 years old were also excluded from this study.

\section{Instruments}

Mental Help-Seeking Attitudes Scale (MHSAS). This scale was developed by Hammer et al. (2018) to assess the overall evaluation of intention to seek help from mental health professionals if they found themselves struggling with mental health issues. The instrument consists of nine items, measured with a 7-point semantic differential scale. Items 2, 5, 6, 8, and 9 are reverse scored. A sample item from this scale includes "If I had a mental health concern, seeking help from a mental health professional would be useful." A higher score indicates favourable and positive attitudes toward seeking help. In the current study, the $\alpha$ coefficient for MHSAS is .92.

Inventory of Attitudes toward Seeking Mental Health Services (IASMHS). Developed by Mackenzie et al. (2004), this scale was used to measure the participants' psychological openness and help-seeking propensity. There are eight items measured with a 5-point Likert scale for this subscale, ranging from 0 (strongly disagree) to 4 (strongly agree) (Yousaf et al., 2015). A sample item from this scale includes "Psychological problems, like many things, tend to work out by themselves." Higher scores reflect higher psychological openness and higher help-seeking propensity. In the current study, the $\alpha$ coefficients for IASMHS are .70 and .85 for psychological openness and help-seeking propensity, respectively.

The Perceived Stigma and Barriers to Care for Psychological Problems. The subscale of perceived public stigma was used to measure one's beliefs about how others would view 
them to seek mental health treatment (Pederson \& Paves, 2014). There are six items measured with a 5-point Likert scale for this subscale, ranging from 1 (strongly disagree) to 5 (strongly agree). A sample item from this scale includes "My peers might treat me differently if I seek help from mental health professional." A higher score reflected greater perceived public stigma and personal stigma. In the current study, the overall $\alpha$ coefficient is 91 .

\section{Results}

Table 1 below summarized the topic-specific characteristics of the respondents in this study.

Table 1: Characteristics of Help-seeking Intention, Psychological Openness, Indifference to Stigma, Help-seeking Propensity

\begin{tabular}{lllllll}
\hline & $M$ & $S D$ & Min & Max & Skewness & Kurtosis \\
\hline Help-seeking Intention & 5.44 & 1.02 & 2.00 & 7.00 & -.312 & -.316 \\
Psychological Openness & 19.35 & 4.94 & 3.00 & 32.00 & -.366 & .461 \\
Indifference to Stigma & 28.15 & 10.01 & 12.00 & 59.00 & .306 & -.395 \\
Help-seeking Propensity & 20.44 & 5.81 & 2.00 & 32.00 & -.098 & -.227 \\
\hline
\end{tabular}

Note. $M=$ mean; $S D=$ standard deviation; $M i n=$ minimum value; Max = maximum value; Skewness $=$ skewness value; Kurtosis $=$ kurtosis value.

Table 2 below shows the correlations of all the variables of the present study.

Table 2: Correlation Table of the Variables

\begin{tabular}{llllll}
\hline Variables & $\mathbf{1}$ & $\mathbf{2}$ & $\mathbf{3}$ & $\mathbf{4}$ & $\mathbf{5}$ \\
\hline Help-seeking Intention & 1 & & & & \\
Psychological Openness & - & 1 & & & \\
& $.220^{* * *}$ & & & & \\
Perceived Public Stigma & - & $.288^{* * *}$ & 1 & & \\
Self-stigma & $.379^{* * *}$ & & & & \\
Help-seeking Propensity & - & $.218^{* * *}$ & $.531^{* * *}$ & 1 & \\
& $.387^{* * *}$ & & & & \\
& $.376^{* * *}$ & .042 & - & .004 & 1 \\
\hline
\end{tabular}

Note. ${ }^{* * *}$ Indicates $p<.001$.

\section{Discussion}

The current study has met the objectives to assess the relationships between help-seeking intention, psychological openness, indifferent to stigma (perceived public stigma and selfstigma), and help-seeking propensity among university students in Malaysia. Results indicated that psychological openness and indifference to stigma (perceived public stigma and selfstigma) were negatively correlated with help-seeking intention, while help-seeking propensity was positively correlated with help-seeking intention. Besides that, these variables (i.e., psychological openness, indifference to stigma, and help-seeking propensity) were found to have significant relationships with help-seeking intention.

A surprising negative relationship was found between help-seeking intention and psychological openness. Contrary to several studies (e.g., Hyland et al., 2015; Pham et al., 2020), individuals with high psychological openness have lower help-seeking intention. The contradictory result is possibly due to psychological openness being a cultural-specific 
variable that may result differently in different cultural contexts. According to David (2010), the help-seeking intention is negatively correlated with psychological openness among Filipino Americans. The researcher explained that even people with high psychological openness might have trust issues with mental health services, which is the main barrier stopping people from seeking professional help. When individuals are not trusting the professionals, they will tend to seek help from people around them instead of the formal resources. For example, people are afraid that their private issues will be revealed and discussed by the counsellor, so they will try to solve the issues by themselves or seek help from family or friends. Besides that, individuals with high levels of psychological openness do not necessarily translate to higher need to seek help in resolving mental health issues. People may have faith in their ability to cope with their predicaments on their own. The severity of the issues may also dictate their consideration to seek help from professionals.

The present study's findings had supported $\mathrm{H}_{2}$, where a negative relationship between helpseeking intention and perceived public stigma was found. The current findings were congruent with Topkaya (2014), which reported that a higher level of perceived public stigma was correlated with a lower help-seeking intention. According to Subramaniam et al. (2017), stigma is considered a social construct as it could be influenced by culture. Malaysian students were ingrained with the perception that people with mental illness are dangerous and disabled (Subramaniam et al., 2017). Cultural values, for example, play an important role in defining causal models of disease and brings meaning to stigma. The key is to dispel the myths surrounding mental health issues and associate mental health issues as medical issues rather than personal weaknesses. Incorporating mental health issues into mainstream education may reduce the stigma originating from misconception, thus increasing the intention to seek help. A study conducted by Salim (2010) concluded that stigma towards mental illness among Malaysian students needs to be reduced to improve the intention to seek help.

In addition, a negative relationship between help-seeking intention and self-stigma was found. This finding is congruent with Topkaya (2014), which reported that a higher level of self-stigma was correlated with lower help-seeking intention. The same results also reported in the study conducted by Nam et al (2013), which indicated that college students with higher levels of self-stigma have less intention to seek help. According to research conducted by Tan et al. (2020), students have low intention to seek help from professionals as they were afraid to be labelled by other people around them. In other words, self-stigma is negatively correlated with help-seeking intention. Based on Kirsh et al (2016), the participant in their research reported that tertiary education students are expected to be good enough in managing their problem, including mental health issues. This expectation has built obstacles for students to seek help as they fear being labelled as weaklings (Kirsh et al., 2016). According to Cheng et al (2018), self-stigma was associated with mental health literacy. For example, a lack of understanding of mental health issues or diseases may lead to self-labelling and isolation. Their intention to seek help from professionals will be drastically reduced (Subramaniam et al., 2017). Education is the key to reduce the level of self-stigma (Milin et al., 2016).

Lastly, the results of the present study had supported $\mathrm{H}_{3}$, where a positive relationship between help-seeking intention and help-seeking propensity was found. This finding is consistent with several other past studies (e.g., Hyland et al., 2015; Pham et al., 2020). The positive relationship between these two variables indicated that students would be more likely to seek professional support if they understand that seeking professional help could improve their psychological well-being (Pham et al., 2020). The understanding is particularly 
critical given the psychological consequences of social isolation and other life disturbances caused by the COVID-19 pandemic. Furthermore, awareness and knowledge levels towards psychological guidance and counselling, which include help-seeking propensity, may affect the help-seeking intention and actual behaviour of the individual, where a positive attitude leads to a higher willingness to seek help (Abhayasinghe, 2014).

\section{Implications}

This study offers a foundation for university students to comprehend the fundamental causes that hinder their intention to seek help from professionals for their mental and psychological health issues. This study provides university students insight into reducing their stigma and improving their help-seeking propensity to improve their help-seeking intention. Counsellors and educators may benefit from the result of the current study to explore factors pertinent to help-seeking intention. To create a healthy environment, universities could help play important roles to advocate and educate students concerning mental health issues.

\section{Limitations and Recommendations}

The purposive sampling method used in the current study is less than ideal for representing the population of interest. Moreover, using a self-reported questionnaire to collect responses may cause biased responses from the participants as they tend to answer the questions based on their social interest.

Future research on this topic may consider adopting probability sampling to increase the generalizability. In addition, future research may expand or improve the existing study by considering variables that may boost help-seeking intention.

\section{Declaration of Conflicting Interests}

The author(s) declared no potential conflicts of interest with respect to the research, authorship, and/or publication

of this article.

\section{Funding}

The author(s) received no financial support for the research, authorship, and/or publication of this article.

\section{Reference}

Abhayasinghe, M. P. K. W. (2014). Knowledge and attitudes towards psychological counselling and guidance among undergraduates in Sri Lanka. International Journal of Current Research, 6(07), 7493-7497.

Ajzen, I. (1985). From intentions to actions: A theory of planned behavior. In Action control (pp. 11-39). Springer, Berlin, Heidelberg.

Alexi, N., Moore, K., \& Argyrides, M. (2018). Openness to help-seeking for mental illness among Greek-Cypriots. Health Promotion International, 33(6), 990-998.

Auerbach, R. P., Alonso, J., Axinn, W. G., Cuijpers, P., Ebert, D. D., Green, J. G., ... \& Nock, M. K. (2016). Mental disorders among college students in the World Health Organization world mental health surveys. Psychological Medicine, 46(14), 2955-2970.

Brown, N., Te Riele, K., Shelley, B., \& Woodroffe, J. (2020). Learning at home during COVID19: Effects on vulnerable young Australians. Peter Underwood Centre for Educational Attainment, University of Tasmania. 
Cheng, H. L., Wang, C., McDermott, R. C., Kridel, M., \& Rislin, J. L. (2018). Self-stigma, mental health literacy, and attitudes toward seeking psychological help. Journal of Counseling \& Development, 96(1), 64-74.

Corrigan, P. (2004). How stigma interferes with mental health care. American Psychologist, 59(7), 614-652.

David, E. J. R. (2010). Cultural mistrust and mental health help-seeking attitudes among Filipino Americans. Asian American Journal of Psychology, 1(1), 57-66.

Fonseca, A., Moura-Ramos, M., \& Canavarro, M. C. (2018). Attachment and mental helpseeking in the perinatal period: The role of stigma. Community Mental Health Journal, 54(1), 92-101.

Hasmuk, K., Sallehuddin, H., Tan, M. P., Cheah, W. K., Ibrahim, R., \& Chai, S. T. (2020). The long term care COVID-19 situation in Malaysia.

https://Itccovid.org/2020/05/22/new-report-the-covid-19-long-term-care-situation-inmalaysia/

Hyland, P., Boduszek, D., Dhingra, K., Shevlin, M., Maguire, R., \& Morley, K. (2015). A test of the inventory of attitudes towards seeking mental health services. British Journal of Guidance \& Counselling, 43(4), 397-412.

Ibrahim, N., Amit, N., Shahar, S., Wee, L. H., Ismail, R., Khairuddin, R., ... \& Safien, A. M. (2019). Do depression literacy, mental illness beliefs and stigma influence mental health help-seeking attitude? A cross-sectional study of secondary school and university students from B40 households in Malaysia. BMC Public Health, 19(4), 544.

Kamimura, A., Trinh, H. N., Johansen, M., Hurley, J., Pye, M., Sin, K., \& Nguyen, H. (2018). Perceptions of mental health and mental health services among college students in Vietnam and the United States. Asian Journal of Psychiatry, 37, 15-19.

Khalid, M. A. (2020). Covid-19: Malaysia Experience and Key Lessons. Asian Economic Papers, 1-26.

Kirsh, B., Friedland, J., Cho, S., Gopalasuntharanathan, N., Orfus, S., Salkovitch, M., ... \& Webber, C. (2016). Experiences of university students living with mental health problems: Interrelations between the self, the social, and the school. Work, 53(2), 325335.

Laidlaw, A., McLellan, J., \& Ozakinci, G. (2016). Understanding undergraduate student perceptions of mental health, mental well-being and help-seeking behaviour. Studies in Higher Education, 41(12), 2156-2168.

Lang, T. (2020). Plug COVID-19 research gaps in detection, prevention and care. Nature. 583, 33.

Liang, S. W., Chen, R. N., Liu, L. L., Li, X., Chen, J. B., Tang, S. Y., \& Zhao, J. (2020). The psychological impact of the COVID-19 epidemic on Guangdong college students: The difference between seeking and not seeking psychological help. Frontiers in Psychology, 11, 1-10.

Luo, C., Li, Y., Chen, A., \& Tang, Y. (2020). What triggers online help-seeking retransmission during the COVID-19 period? Empirical evidence from Chinese social media. Plos one, 15(11).

Mackenzie, C. S., Erickson, J., Deane, F. P., \& Wright, M. (2014). Changes in attitudes toward seeking mental health services: A 40-year cross-temporal meta-analysis. Clinical Psychology Review, 34(2), 99-106.

Milin, R., Kutcher, S., Lewis, S. P., Walker, S., Wei, Y., Ferrill, N., \& Armstrong, M. A. (2016). Impact of a mental health curriculum on knowledge and stigma among high school 
students: A randomized controlled trial. Journal of the American Academy of Child \& Adolescent Psychiatry, 55(5), 383-391.

Nam, S. K., Choi, S. I., Lee, J. H., Lee, M. K., Kim, A. R., \& Lee, S. M. (2013). Psychological factors in college students' attitudes toward seeking professional psychological help: A meta-analysis. Professional Psychology: Research and Practice, 44, 37-45.

Pham, N. C., Li, Y., Hossain, T., Schapsis, C., Pham, H. H., \& Minor, M. (2020). Understanding mental health services and help-seeking behaviours among college students in Vietnam. Asia Pacific Journal of Health Management, 15(3), 58-71.

Salim, S. (2010). Psychological help seeking attitudes among Malaysian college and university students. Procedia-Social and Behavioral Sciences, 5, 426-430.

Shanmugam, H., Juhari, J. A., Nair, P., Ken, C. S., \& Guan, N. C. (2020). Impacts of COVID-19 pandemic on mental health in Malaysia: A single thread of hope. Malaysian Journal of Psychiatry, 29(1).

Son, C., Hegde, S., Smith, A., Wang, X., \& Sasangohar, F. (2020). Effects of COVID-19 on college students' mental health in the United States: Interview survey study. Journal of Medical Internet Research, 22(9), e21279.

Subramaniam, M., Abdin, E., Picco, L., Pang, S., Shafie, S., Vaingankar, J. A., ... \& Chong, S. A. (2017). Stigma towards people with mental disorders and its components-a perspective from multi-ethnic Singapore. Epidemiology and Psychiatric Sciences, 26(4), 371-382.

Tan, G. T. H., Shahwan, S., Goh, C. M. J., Ong, W. J., Samari, E., Abdin, E., ... \& Subramaniam, M. (2020). Causal beliefs of mental illness and its impact on help-seeking attitudes: A cross-sectional study among university students in Singapore. BMJ Open, 10(7), e035818.

Topkaya, N. (2014). Gender, self-stigma, and public stigma in predicting attitudes toward psychological help-seeking. Educational Sciences: Theory and Practice, 14(2), 480-487.

Troeung, L., Gasson, N., \& Egan, S. J. (2015). Patterns and predictors of mental health service utilization in people with Parkinson's disease. Journal of Geriatric Psychiatry and Neurology, 28, 12-18.

Tschofen, C., \& Mackness, J. (2012). Connectivism and dimensions of individual experience. The International Review of Research in Open and Distance Learning, 13(1), 124-143.

Umubyeyi, A., Mogren, I., Ntaganira, J., \& Krantz, G. (2016). Help-seeking behaviours, barriers to care and self-efficacy for seeking mental health care: A population-based study in Rwanda. Social Psychiatry and Psychiatric Epidemiology, 51(1), 81-92.

Yee, H. S. (2018). Stigma of mental illness and attitudes towards seeking mental health services among undergraduates in a public university in Malaysia. In Universitas Indonesia International Psychology Symposium for Undergraduate Research (UIPSUR 2017). Atlantis Press.

Zhang, H., Su, H., Wang, D., Wang, L., Cai, Y., \& Zhou, Y. (2020). COVID-19: Are you ready to seek psychological help during home quarantine? ResearchSquare, 1-12. 